Article

\title{
Collaborative Optimization of Multi-Energy Complementary Combined Cooling, Heating, and Power Systems Considering Schedulable Loads
}

\author{
Xiao Gong, Fan Li, Bo Sun * and Dong Liu \\ School of Control Science and Engineering, Shandong University, Jinan 250061, China; \\ xiao_gong1109@163.com (X.G.); lifan_12_12@163.com (F.L.); liudong19936@163.com (D.L.) \\ * Correspondence: sunbo@sdu.edu.cn
}

Received: 9 December 2019; Accepted: 13 February 2020; Published: 18 February 2020

check for updates

\begin{abstract}
Combined cooling, heating, and power (CCHP) systems are a promising energy-efficient and environment-friendly technology. However, their performance in terms of energy, economy, and environment factors depends on the operation strategy. This paper proposes a multi-energy complementary CCHP system integrating renewable energy sources and schedulable heating, cooling, and electrical loads. The system uses schedulable loads instead of energy storage, at the same time, a collaborative optimization scheduling strategy, which integrates energy supply and load demand into a unified optimization framework to achieve the optimal system performance, is presented. Schedulable cooling and heating load models are formulated using the relationship between indoor and outdoor house temperatures. A genetic algorithm is employed to optimize the overall performance of energy, economy, and environment factors and obtain optimal day-ahead scheduling scheme. Case studies are conducted to verify the efficiency of the proposed method. Compared with a system involving thermal energy storage and demand response (DR), the proposed method exhibits a higher primary energy saving rate, greenhouse gas emission reduction rate, and operation costs saving rate of $7.44 \%, 6.59 \%$, and $4.73 \%$, respectively, for a typical summer day, thereby demonstrating the feasibility and superiority of the proposed approach.
\end{abstract}

Keywords: combined cooling heating and power (CCHP) system; demand response; schedulable loads; collaborative optimization scheduling; day-ahead optimization

\section{Introduction}

Energy and environmental issues are key challenges for future global sustainable development [1,2]. Combined cooling, heating and power (CCHP) systems, with the environmental benefits based on their use of waste heat recovery technology and the energy cascade utilization principle, which have attracted considerable research attention. A CCHP system generates both electricity and useful cooling/heating energy to convert $75-80 \%$ of a fuel source into usable energy. Renewable energy sources (RESs) are expected to account for increased energy consumption due to significant environmental benefits, and can be better used in conjunction with CCHP systems [3]. The efficient operation of the system depends on the energy supply and demand matching, but the variation of load in actual operation will cause the mismatch between the energy supply and demand [4].

Thermal energy storage (TES) units are an effective method for CCHP systems to reduce the mismatch between the energy supply and demand, and improve the energetic and economic performances [4,5]. Xu et al. studied a smart building energy system comprising a CCHP system, RESs, and various energy storage devices, taking into account the uncertainty of demand and solar radiation [6]. Liu et al. proposed a CCHP system with TES as an energy station [7]. Mohammadkhani et al. proposed 
a residential microgrid equipped by $\mathrm{CCHP}$ with considering electrical energy storage and thermal energy storage [8].

Demand response (DR) is also an effective way to deal with source-load mismatch and improve operation efficiency, replacing energy storage to a certain extent and reducing installation costs. DR is defined as "changes in electric usage by end-use customers from their normal consumption patterns in response to changes in the price of electricity over time, or to incentive payments designed to induce lower electricity use at times of high wholesale market prices or when system reliability is jeopardized" [9]. Aalami et al. proposed an incentive-based DR model considering interruptible/ curtailable loads, using the price elasticity of demand and the customer benefit function, which improved the characteristics of the load curve and was also welcomed by customers [10]. Ghazvini et al. verified the performance of an intelligent home energy management system algorithm to schedule the consumption of controllable devices in a smart household [11]. Zakariazadeh et al. demonstrated that the adoption of DR programs can reduce total operation costs and improve energy efficiency [12].

The operation strategy is a key factor that determines the success of application, energy performance, and environmental benefits of the CCHP system $[13,14]$, especially for efficient operation of the system with TES and DR $[15,16]$. However, the basic operation mode, including following thermal load (FTL) and following electric load (FEL), has limited ability to optimize the system operation. Wang et al. [17] proposed an improved FEL operation strategy and Feng et al. [18] proposed an improved hybrid load tracking method (FHL) based on a comparison between FEL and FTL strategies. Ma et al. developed a seasonal operation strategy for a new distributed energy system integrating CCHP, photovoltaics, and a ground source heat pump (GSHP), which improved the system performance index [19]. Cao et al. developed a configuration optimization framework that extends existing energy system optimization studies in following four aspects: complete system optimization from the beginning, comprehensive energy conversion equipment modeling, modeling of cascaded configurations, and consideration of transient loads and weather profiles [20]. Luo et al. proposed a new two-stage coordinated control method for managing the energy of the CCHP micro-grid, including an economic dispatch stage (EDS) and a real-time adjustment stage (RTAS), and conducted simulations to verify the performance of the method [21]. Afzali et al. divided the operation of the CCHP system into three cases according to the capacity of the gas turbine, thermal load, and electrical load and gave the analytical expression for the ratio of electricity price to natural gas price [22]. Li et al. proposed a hybrid optimization method that combines the GA and dynamic programming (DP) to obtain the optimal scheduling scheme for CCHP system with TES [23]. Deng et al. proposed an optimal scheduling strategy based on actual operation of an energy station with energy storage and a GSHP to minimize daily operating costs [24]. Zheng et al. proposed a new thermal storage strategy (TSS), which determined the operating state of the PGU according to the power demand, thermal demand, and state of the thermal storage device. Results show that the TSS improves the performance of CCHP systems compared to traditional strategies [25]. Kuang et al. proposed a dynamic optimization method for CCHP systems with energy storage, and obtained the most economical operation scheme in a very short time by adopting a dynamic solution framework [26].

In summary, most research has focused on optimizing the energy supply and storage strategies to improve the system performance index and meet users' demands. A small number of studies have focused only on DR program, which mainly involving the use of time-of-use electricity prices to achieve the electricity load transfer. Few studies have carried out the management of cooling and heating load. In fact, cooling and heating load account for $70-80 \%$ of the building load. Load demand side management can coordinate the adjustment of cooling and heating, without additional equipment to reduce the mismatch between the energy supply and demand.

This paper proposes a collaborative optimization scheduling strategy for a multi-energy complementary CCHP system consisting of solar photovoltaics (PVs), wind turbines (WTs), a power generation unit (PGU), a heat pump (HP), an absorption chiller (AC). The system uses schedulable loads, including schedulable cooling, heating, and electrical loads, instead of energy storage. The 
scheduling of load demand and energy supply is unified into a collaborative optimization model. Comprehensive evaluation indexes of the economy, environment, and energy performance are chosen as the optimization objectives, and GA is used to solve the optimization problem. Case studies are conducted on a residential building to verify the effectiveness of the proposed approach. The main contributions of this paper are as follows:

- A schedulable cooling and heating load model is established using the indoor and outdoor temperature relationships of a house, and the demand side management for multiple types of loads was achieved.

- The system energy supply and load demand are included in the unified optimization scheduling framework, and a multi-objective collaborative optimization scheduling model is established to achieve global optimization of day-ahead scheduling.

- Compared with the RESs CCHP system containing energy storage and DR, the proposed method achieves better performance indexes and reduces system complexity.

The remainder of this paper is organized as follows: Section 2 details the system structure and energy flow. Section 3 presents the optimal scheduling model and solution method. The case studies and results are discussed in Section 4. Finally, Section 5 presents the main conclusions.

\section{System Description}

\subsection{System Structure}

The multi-energy complementary CCHP system structure and energy flow diagram are shown in Figure 1. Solar PVs and WTs are used to supply electricity for CCHP system. The PGU consumes natural gas to generate electricity. The insufficient electricity purchases from public utility grid. The heating and cooling mode of the CCHP system are studied, respectively. In heating mode (Figure 1a), the waste heat generated by the PGU is recovered by the heat recovery unit to supply the heat load, and the insufficient heat is met by the HP. And in cooling mode (Figure 1b), the recovered waste heat is used to drive AC to supply cooling, the deficient cooling is satisfied by HP.

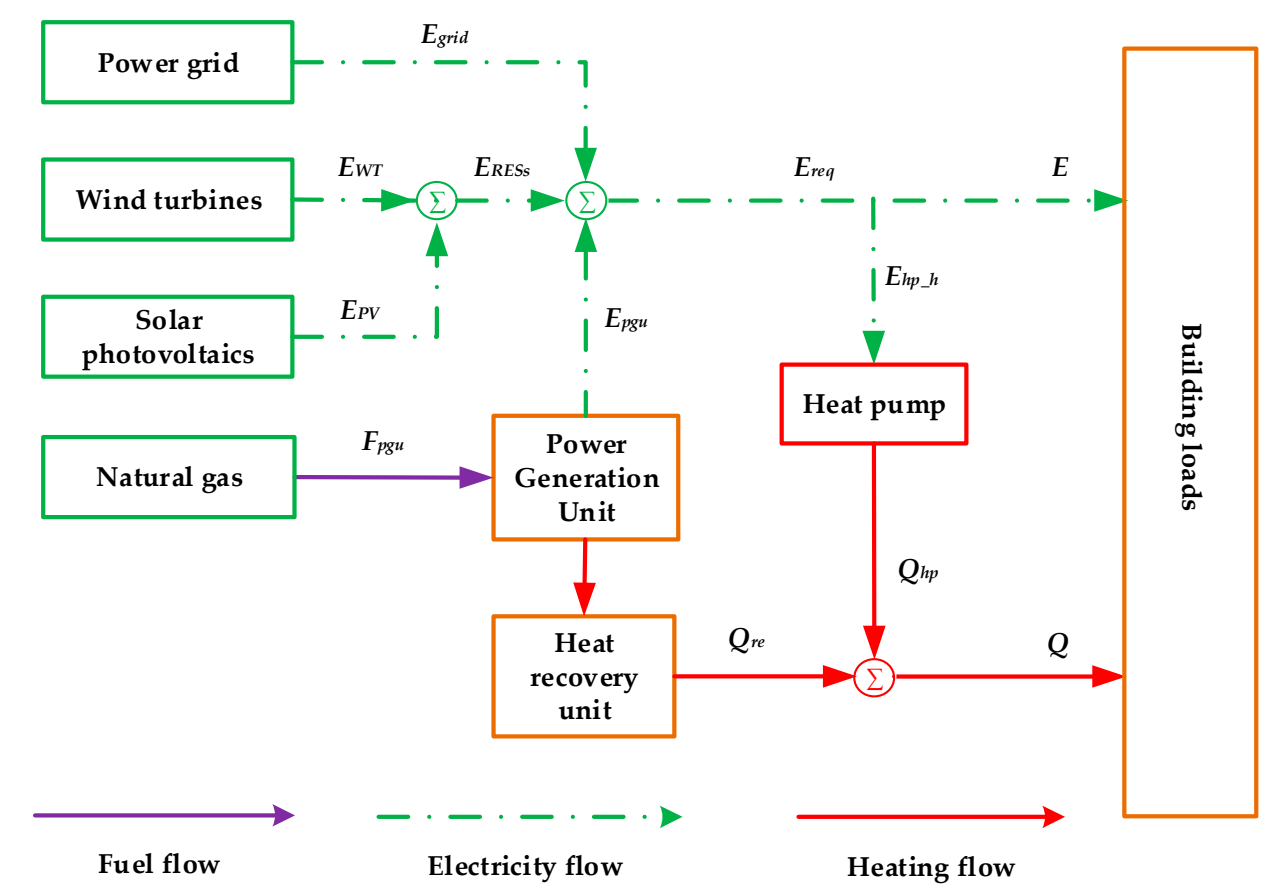

(a) CCHP system structure and energy flow in heating mode

Figure 1. Cont. 


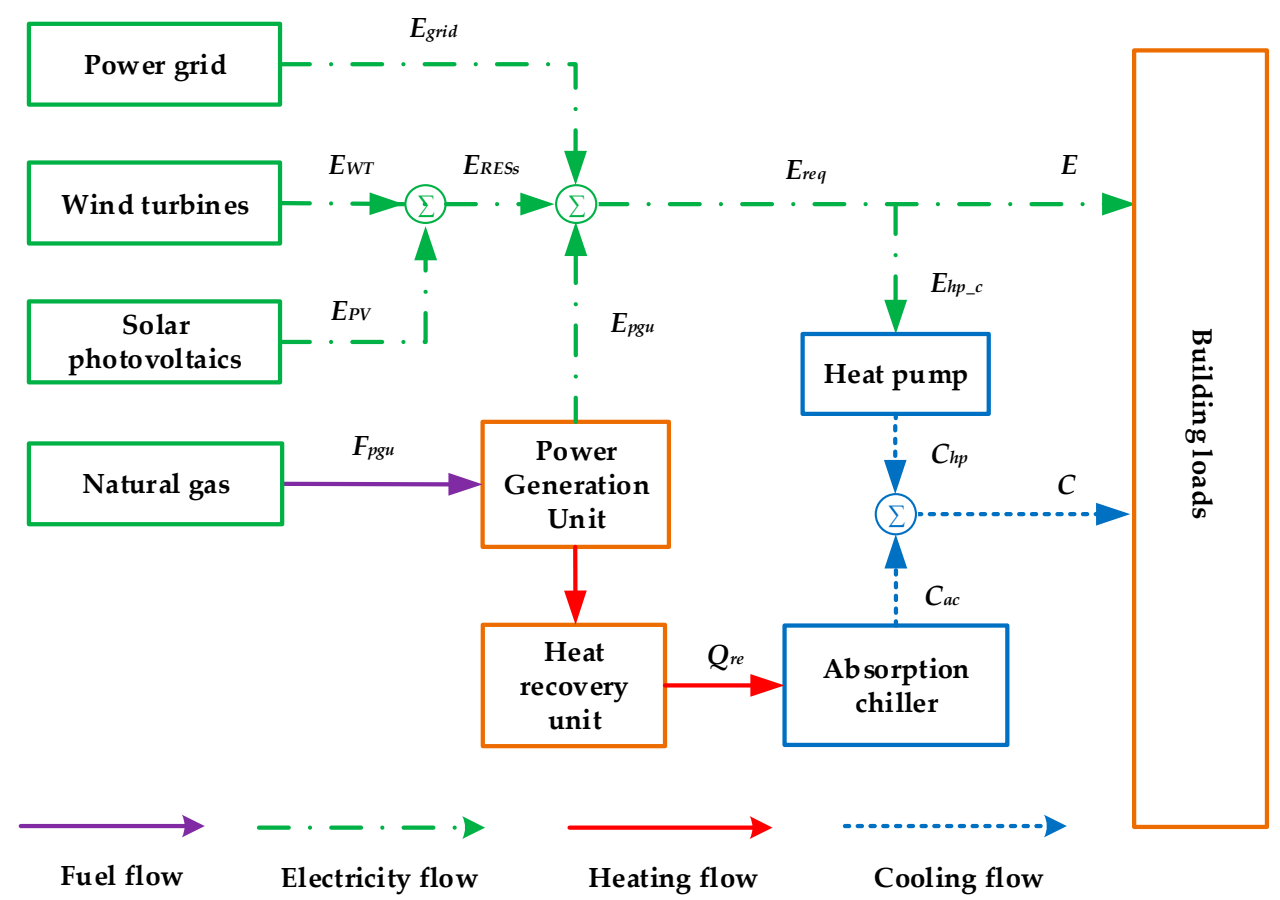

(b) CCHP system structure and energy flow in cooling mode

Figure 1. Structure and energy flow of the multi-energy complementary CCHP system.

\subsection{Energy Flow Analysis}

As shown in Figure 1, the energy flow of a residential hybrid cogeneration system is divided into the electricity energy balance, heating energy balance, and cooling energy balance. The electricity energy balance in the multi-energy complementary CCHP system is expressed as follows:

$$
E_{R E S s}(t)+E_{p g u}(t)+E_{g r i d}(t)=E(t)+E_{a c}(t)+E_{h p}(t),
$$

where $E_{R E S s}(t)$ and $E_{p g u}(t)$ are the electricity generated by the RESs and PGU in period $t$, respectively; $E_{\text {grid }}(t)$ is the electricity purchased from the grid in period $t ; E_{a c}(t)$ and $E_{h p}(t)$ represent the electricity consumption of the AC and HP in period t, respectively; $E(t)$ is the electricity load of buildings (excluding $\mathrm{HP}$ and $\mathrm{AC}$ consumption electricity) in period t. $E_{R E S S}(t)$ can be estimated as given below:

$$
E_{R E S s}(t)=E_{P V}(t)+E_{W T}(t),
$$

where $E_{P V}(t)$ and $E_{W T}(t)$ are the electricity generated by solar PVs and WTs in period $t$, respectively. In addition, $E_{p g u}(t)$ can be represented as below:

$$
E_{p g u}(t)=F_{p g u}(t) \eta_{e l} \eta_{t h}
$$

where $F_{p g u}(t)$ is the fuel consumption of the PGU in period $t$, and $\eta_{e l}$ and $\eta_{t h}$ are the electrical efficiency and thermal efficiency of the PGU, respectively, both of which are subject to the PLR of the PGU and expressed as follows [27]:

$$
\begin{aligned}
& \eta_{e l}=a_{0}+a_{1} P L R+a_{2} P L R^{2}, \\
& \eta_{\text {th }}=b_{0}+b_{1} P L R+b_{2} P L R^{2},
\end{aligned}
$$

where $a_{0}, a_{1}, a_{2}, b_{0}, b_{1}$, and $b_{2}$ are determined by particular PGU. PLR is the part-load ratio of the PGU and given as follows:

$$
P L R=\frac{E_{p g u}(t)}{E_{p g u, n o m}}
$$


where $E_{p g u, n o m}$ is the nominal capacity of the PGU.

PGU has low electrical efficiency when running at a low PLR. Therefore, a parameter $\lambda(0 \leq \lambda \leq 1)$ is proposed to limit the lower limit of PLR of PGUs. The electricity generated by the PGU is defined as:

$$
E_{p q u}(t)=\left\{\begin{array}{ll}
0, & 0 \leq P L R<\lambda \\
E_{p q u}(t), & \lambda \leq P L R \leq 1 \\
E_{p g u, n o m}, & P L R>1
\end{array},\right.
$$

Meanwhile, $E_{h p}(t)$ is expressed as follows:

$$
\begin{gathered}
E_{h p}(t)=E_{h p \_h}(t)+E_{h p_{\_} c}(t), \\
E_{h p \_h}(t)=Q_{h p}(t) / C O P_{h}, \\
E_{h p_{\_} c}(t)=C_{h p}(t) / C O P_{c},
\end{gathered}
$$

where $E_{h \__{-} h}(t)$ and $E_{h p_{-} c}(t)$ represent the electricity consumed by the heat pump heating and cooling in period $t ; Q_{h p}(\mathrm{t})$ and $C_{h p}(t)$ are the heating and cooling effects, respectively, generated by the heat pump in period $\mathrm{t}$; and $\mathrm{COP}_{h}$ and $C O P_{c}$ are the coefficients of heat pump performance in heating mode and cooling mode, respectively.

$E_{\text {grid }}(t)$ can be transformed into primary energy consumption as follows:

$$
F_{\text {grid }}(t)=\frac{E_{\text {grid }}(t)}{\eta_{e, \text { grid }} \eta_{t, \text { grid }}}
$$

where $F_{\text {grid }}(t)$ represents the coal consumed by the electricity generation via the grid in period $\mathrm{t}$ and $\eta_{e, \text { grid }}$ and $\eta_{t, \text { grid }}$ are the electricity generation efficiency and electricity transmission efficiency of the grid, respectively.

The heating energy balance in the multi-energy complementary CCHP system is expressed as below:

$$
Q_{r e}(t)+Q_{h p}(t)=Q(t),
$$

where $Q_{r e}(t)$ represents the recovery waste heat of the PGU in period $t$ and $Q(t)$ is the heating load of buildings in period $t$. $Q_{r e}(t)$ can also be represented as below [7]:

$$
Q_{r e}(t)=F_{p g u}(t)\left(1-\eta_{t h}\right) \eta_{r}
$$

where $\eta_{r}$ is the efficiency of the heat recovery unit.

The cooling energy balance in the multi-energy complementary CCHP system is expressed as follows:

$$
C_{a c}(t)+C_{h p}(t)=C(t),
$$

where $C(t)$ is the cooling load of buildings in period $t$ and $C_{a c}(t)$ is the output cooling energy of the AC in period $t$ :

$$
C_{a c}(t)=Q_{a c \_i n}(t) C O P,
$$

here, $Q_{a c \_ \text {in }}(t)$ represents the heat entering the $\mathrm{AC}$ in period $t$ and $\mathrm{COP}$ is the coefficient of performance for the AC.

\subsection{Schedulable Loads Analysis}

The schedulable loads are critical for the collaborative optimization model. We analyze the schedulable model of the electricity, heating, and cooling loads of the system. 


\subsubsection{Schedulable Electricity Load}

Appliances with $40 \%$ residential power consumption (such as washers and dryers) exhibit great potential for loading shifting [28]. These appliances, which are sensitive to electricity prices and incentive signals, are called schedulable loads. Schedulable loads can be divided into interruptible and uninterruptible loads. Interruptible loads such as electric vehicle charging should be suspended during peak hours. Other electric appliances, such as electric cookers and water heaters, are uninterruptible once started. Load shifting in a finite time is introduced instead of load curtailment due to the willingness of residential customers in DR programs.

If $I$ is the set of schedulable smart electric appliances belonging to low timeliness orders in the horizon $T, I_{\mathrm{c}}$ is the set of interruptible appliances in $I$, the appliances in the working interval can be opened and closed at any time according to personal habits; $I_{U}$ is the set of uninterruptible appliances in $I$, once it is running, the appliances shall not be closed within the working interval. And $t$ is the period index $(t=1,2, \ldots, 24)$, then for each appliance $i \in I$, the energy consumption and on/off state in interval $t \in T$ can be described as $e_{i}(\mathrm{t})$ and $y_{i}(t) \in\{0,1\}$, respectively. For simplicity, we assume that the consumption power of each appliance is fixed in a single interval, defined as $r_{i}$. $\left[A_{i}, B_{i}\right] \in T$ is defined as the working interval of device $i$. Considering that the total consumption of devices participating in demand response is determinate, consumed energy $e_{i}(\mathrm{t})$ in period $\mathrm{t}$ is subject to the following constraints:

$$
\sum_{t=A_{i}}^{B_{i}} e_{i}(t)=E_{i}, \forall i \in I,
$$

where $E_{i}$ is the total energy consumption for device $i$ in the working interval. The actual minimum/maximum completion time index is $\tau_{i, \min }$ and $\tau_{i, \max }$ in horizon T. Clearly,

$$
\tau_{i, \min } \leq \sum_{t=A_{i}}^{B_{i}} y_{i}(t) \leq \tau_{i, \max }, \forall i \in I,
$$

where the completion time index is assigned as $\tau^{i}$.

Moreover, some electric devices are run in the early morning and at night; i.e., the working interval can be described as $\left[1, j_{1}\right] \cup\left[j_{2}, 24\right], j_{1}<j_{2}$. Devices with intermittent working intervals are divided into two independent types. If $t \notin\left[A_{i}, c\right]$, then $y_{i}(t)=0$. For interruptible loads, $y_{i}(t)$ can be 0 or 1 without limit in $\left[A_{i}, B_{i}\right]$. Nevertheless, for uninterruptible devices, $i \in I_{U}$, an auxiliary binary variable $\mu_{i}(t)$ is introduced to describe the running state. When a device is running, $\mu_{i}(t)=1$; otherwise, $\mu_{i}(t)=0$. Thus:

$$
\begin{gathered}
\sum_{t=A_{i}}^{B_{i}}-\tau_{i}+1 \mu_{i}(t)=1, \forall i \in I_{U}, \\
\mu_{i}(t)=0, \forall i \notin\left[A_{i}, B_{i}-\tau_{i}+1\right],
\end{gathered}
$$

The above equation indicates that device $i$ would start at some time during interval $\left[A_{i}, B_{i}-\right.$ $\left.\tau_{i, \text { min }}+1\right]$ and finish by time $B_{i}$. The following inequation can be derived to relate $y_{i}(t)$ and $\mu_{i}(t)$ :

$$
y_{i}(t) \geq \mu_{i}(t), y_{i}(t+1) \geq \mu_{i}(t), \ldots y_{i}\left(t+\tau_{i}-1\right) \geq \mu_{i}(t), \forall t \in T, i \in I,
$$

\subsubsection{Schedulable Heating and Cooling Loads}

By the differential equation of the indoor and outdoor temperature of the house [29]:

$$
\begin{gathered}
\frac{d Q_{\text {losses }}}{d t}=\frac{T_{\text {in }}-T_{\text {out }}}{R_{\text {eq }}}, \\
\frac{d T_{\text {in }}}{d t}=\frac{1}{M_{\text {air }} \cdot c}\left(\frac{d Q_{\text {house }}}{d t}-\frac{d Q_{\text {losses }}}{d t}\right),
\end{gathered}
$$


where $T_{\text {in }}$ and $T_{\text {out }}$ are the indoor and outdoor temperature, respectively; $Q_{\text {losses }}$ and $R_{\text {eq }}$ represent the energy losses and equivalent thermal resistance of the house; $M_{\text {air }}$ and c are the air quality of the house and the specific heat capacity of the air; $Q_{\text {house }}$ is the supplied energy of the house.

Simultaneous (21) and (22), $Q_{\text {house }}$ can be obtained:

$$
Q_{\text {house }}(t)=\left(\left(T_{\text {in }}(t)-T_{\text {in }}(t-1) e^{\varphi T}\right) /\left(1-e^{\varphi T}\right)-T_{\text {out }}(t)\right) / R_{\text {eq }},
$$

where $T$ represents the control period. $R_{e q}$ is expressed as follows:

$$
R_{\text {eq }}=R_{\text {wall }} R_{\text {window }} /\left(R_{\text {wall }}+R_{\text {window }}\right),
$$

where $R_{\text {wall }}$ and $R_{\text {window }}$ are the wall and window thermal parameter of the house, respectively.

Consider the effect of electrical equipment on the heating load, we can get the formula:

$$
Q(t)=\left(\left(T_{\text {in }}(t)-T_{\text {in }}(t-1) e^{\varphi T}\right) /\left(1-e^{\varphi T}\right)-T_{\text {out }}(t)\right) / R_{\text {eq }}-\alpha E(t),
$$

where $Q(t)$ is the heating load in period $t, \alpha$ is the influence coefficient of indoor electrical equipment on the heating load, and $\phi$ is a constant that can be calculated using the following equation:

$$
\varphi=-1 /\left(M_{\text {air }} \cdot c \cdot R_{e q}\right),
$$

Similarly, the schedulable cooling load is represented by the following expression:

$$
C(t)=\left(\left(T_{\text {out }}(t)-\left(T_{\text {in }}(t)-T_{\text {in }}(t-1) e^{\varphi T}\right) /\left(1-e^{\varphi T}\right)\right) / R_{\text {eq }}+\beta E(t),\right.
$$

where $\beta$ is the influence coefficient of indoor electrical equipment on the cooling load.

\section{Optimal Optimization Model}

\subsection{Optimization Variables}

Based on the building load characteristics, the optimal model typically selects $24 \mathrm{~h}$ as the calculation period [27]. The optimization variables are determined by considering the hourly optimal set-point of each unit and the relevant parameters of the schedulable loads comprehensively. According to the system electricity energy balance, optimizing $E_{\text {pgu }}(t)$ can result in control of source-side power generation, whereas optimizing the switching state of the intelligent appliances $\mu_{i}(t)$ can result in the management of the load-side electric load. Based on the balance of system cooling and heating energy, controlling $\mathrm{T}_{\text {in }}(\mathrm{t})$ can manage the cooling and heating load on the load side. Therefore, $\mathrm{E}_{\mathrm{pgu}}(\mathrm{t}), \mu_{\mathrm{i}}(\mathrm{t})$, and $T_{\text {in }}(t)$ are chosen as global optimization variables for the collaborative optimal scheduling model proposed in this paper. Thus, the energy supply side and load side of the system are integrated into a unified optimization framework. The optimization variables are shown in Table 1.

Table 1. Optimization variables for the collaborative optimal scheduling model.

\begin{tabular}{cc}
\hline Optimization Variables & Constraint \\
\hline$E_{\text {pgu }}(\mathrm{t})(\mathrm{t}=1,2, \ldots 24)$ & $0 \leq E_{\text {pgu }}(t) \leq E_{\text {pgu,nom }}$ \\
$\mu_{\mathrm{i}}(\mathrm{t})(i=1.2 \ldots \mathrm{n}, \mathrm{t}=1,2, \ldots 24)$ & $\sum_{t=A_{i}}^{B_{i}-\tau_{i}+1} \mu_{i}(t)=1, \forall i \in I_{U}$ \\
$T_{\text {in }}(\mathrm{t})(\mathrm{t}=1,2, \ldots 24)$ & $\mu_{i}(t)=0, \forall i \notin\left[A_{i}, B_{i}-\tau_{i}+1\right]$ \\
\hline
\end{tabular}

\subsection{Objective Function}

Taking the separated production (SP) system as a reference, the comprehensive evaluation index (CEI) of CCHP involves three factors: energy, the environment, and the economy. And the SP system 
is referred to Figure 3 in [30]. In SP system, electricity is purchased from the grid to meet the electrical load, and electric refrigerator provides cooling load, the heating load is satisfied by the boiler.

\subsubsection{Energy Index}

The primary energy saving ratio (PESR) is based on the first law of thermodynamics and directly reflects the operational efficiency of CCHP compared to a traditional separate production system (SP). It is expressed as follows:

$$
\text { PESR }=\frac{\sum_{t=1}^{24} F_{s p}(t)-\sum_{t=1}^{24} F_{c c h p}(t)}{\sum_{t=1}^{24} F_{s p}(t)},
$$

where $F_{s p}(t)$ and $F_{c c h p}(t)$ represent the total energy consumption of SP and CCHP systems in period $t$, respectively. $F_{c c h p}(t)$ can be calculated using the following:

$$
F_{c c h p}(t)=F_{p g u}(t)+F_{\text {grid_cchp }}(t),
$$

For convenient computation, all energy consumption is converted into a standard coal equivalent, where $1 \mathrm{~kg}$ of standard coal yields approximately $9.33 \mathrm{kWh}$ of energy.

\subsubsection{Environmental Index}

Emissions of greenhouse gases (GHGs), including $\mathrm{CO}_{2}, \mathrm{CH}_{4}, \mathrm{NO}_{\mathrm{x}}$, and $\mathrm{SO}_{2}$, are used to quantitatively evaluate the environmental effects of the energy system. The GHG emission reduction rate (ERR), which indicates the environmental benefits of CCHP compared to SP, is calculated using the following formula:

$$
E R R=\frac{\sum_{t=1}^{24} V_{s p}(t)-\sum_{t=1}^{24} V_{c c h p}(t)}{\sum_{t=1}^{24} V_{s p}(t)},
$$

where $V_{s p}(t)$ and $V_{c c h p}(t)$ are the GHG emissions of the SP system and CCHP system, respectively:

$$
\begin{gathered}
V_{s p}(t)=\sum_{g=1}^{G}\left(F_{\text {grid_sp }}(t) \eta_{\text {grid }}(g)\right), \\
V_{c c h p}(t)=\sum_{g=1}^{G}\left(F_{p g u}(t) \eta_{p g u}(g)+F_{\text {grid_cchp }}(t) \eta_{\text {grid }}(g)\right),
\end{gathered}
$$

here, $\eta_{g r i d}(g)$ and $\eta_{p g u}(g)$ are the GHG g emission coefficients of coal power and gas combustion, $\mathrm{G}$ is the number of GHG respectively. In this study, network electricity is regarded as coal power because approximately $70 \%$ of the network electricity generated in China in 2016 came from coal combustion.

\subsubsection{Economic Index}

The operation costs saving rate (OCSR) is used to evaluate the economic advantages of the proposed multi-energy complementary CCHP system compared to the conventional SP system. The OCSR is described using the following formula:

$$
\operatorname{OCSR}=\frac{\sum_{t=1}^{24} C_{s p}(t)-\sum_{t=1}^{24} C_{c c h p}(t)}{\sum_{t=1}^{24} C_{s p}(t)},
$$

where $C_{s p}(t)$ and $C_{c c h p}(t)$ represent the energy consumption of the SP system and CCHP system in period $t$, respectively; both of these include the cost of fuel and electricity purchased from utility electricity. 


\subsubsection{Comprehensive Evaluation Index (CEI)}

Based on the economic, environmental, and energy indexes, a CEI is established as follows:

$$
C E I=\omega_{1} P E S R+\omega_{2} E R R+\omega_{3} O C S R,
$$

where $\omega_{1}, \omega_{2}, \omega_{3}$ are the weight coefficients of the three indexes, respectively, where $0 \leq \omega_{1}, \omega_{2}, \omega_{3} \leq 1$ and $\omega_{1}+\omega_{2}+\omega_{3}=1$, without loss of generality. This study uses $\omega_{1}=\omega_{2}=\omega_{3}=1 / 3$ [27]. The CEI is used as the optimization objective to determine the trade-off between PESR, ERR, and OCSR. The objective function can be expressed as follows:

$$
\text { Fun }=\max \left\{\omega_{1} P E S R+\omega_{2} E R R+\omega_{3} O C S R\right\},
$$

\subsection{Constraints}

Considering the actual optimal operating process, the optimization model should not only meet the constraints from Equations (1) to (27) but also satisfy the inequality constraints of the main equipment of the system, as below:

$$
\begin{gathered}
0 \leq E_{p g u}(t) \leq E_{p q u, n o m}, \\
0 \leq Q_{h p}(t) \leq Q_{h p \_ \text {max }}, \\
0 \leq C_{h p}(t) \leq C_{h p \_\max }, \\
0 \leq C_{a c}(t) \leq C_{a c \_ \text {max }},
\end{gathered}
$$

Equation (36) is the PGU capacity constraint and Equations (37)-(39) are the upper capacity bounds of the HP and the AC, respectively. Considering human perception, indoor temperatures in the schedulable loads should meet the following comfort constraints:

$$
T_{\text {in_min }} \leq T_{\text {in }}(t) \leq T_{\text {in_max }}
$$

\subsection{Solution Algorithm}

The proposed formulation constructs a collaborative optimal scheduling model; its solution flow chart is shown in Figure 2.

The parameters of the GA algorithm, upper and lower bounds of the variables, technical parameters of the CCHP system, user load, cost parameters, and appliance operational parameters are the initial inputs. The objective function in Equation (35) is evaluated after the optimization of variables and population is initialized. When the average change in the fitness value is less than the values of the options, the optimal variables of the CCHP system are determined. 


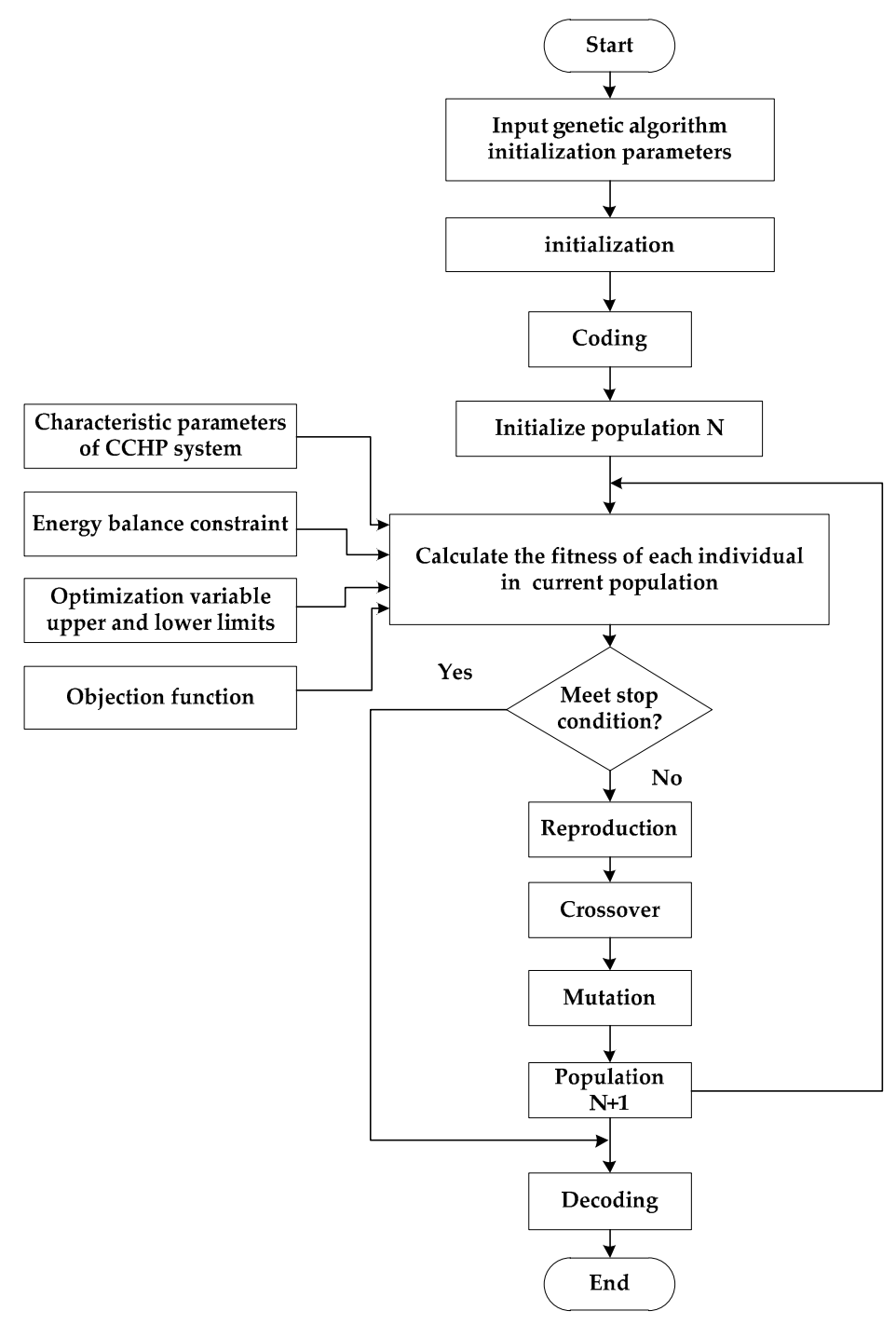

Figure 2. Solution flow chart for the collaborative optimal scheduling model in the genetic algorithm.

\section{Case Analysis}

The scheduling model described in Section 3 is applied to a residential building in Jinan, China, which is used as the subject of day-ahead scheduling. Solar PVs and WTs are used as RESs to supply electricity for CCHP system, and the equations for TES is referred to Equations (14) and (15) in [31]. The equations for DR are Equations (16)-(20) in Section 2.3.1. Four cases are compared (Table 2). Case 1 involves a common CCHP system without a schedulable heating/cooling load or DR programs. In case 2, the TES device is integrated with CCHP to compare system performances.

Table 2. Summary of the cases analyzed in this study.

\begin{tabular}{ccccc}
\hline Case Studies & $\begin{array}{c}\text { Renewable Energy } \\
\text { Sources (RESs) }\end{array}$ & $\begin{array}{c}\text { Thermal Energy } \\
\text { Storage (TES) }\end{array}$ & $\begin{array}{c}\text { Schedulable } \\
\text { Heating/Cooling Load }\end{array}$ & $\begin{array}{c}\text { Demand } \\
\text { Response (DR) }\end{array}$ \\
\hline Case 1 & $\sqrt{ }$ & $\sqrt{ }$ & \\
Case 2 & $\sqrt{ }$ & $\sqrt{ }$ & $\sqrt{ }$ \\
Case 3 & $\sqrt{ }$ & $\sqrt{ }$ & $\sqrt{ }$ \\
Case 4 & $\sqrt{ }$ & & \\
\hline
\end{tabular}

In case 3, the TES and DR devices are integrated with CCHP, with a set of controllable smart appliances used to conduct the DR programs. Case 4 is the proposed comprehensive optimal scheduling 
problem that considers both DR and the schedulable heating/cooling load without TES. The simulation results are compared and discussed in Section 4.2.

\subsection{System Parameters}

System parameters consist mainly of the technical parameters of the components, market information, emissions coefficients, and data on RESs and the residential load. The building parameters are shown in Table 3.

Table 3. Building parameters used in the cases analyzed in this study.

\begin{tabular}{ccc}
\hline Parameter & Value & Unit \\
\hline$R_{e q}$ & $4.27 \times 10^{-7}$ & $\mathrm{~m}^{2} \mathrm{~K} / \mathrm{W}$ \\
$\phi$ & -1.3099 & - \\
$\alpha$ & 0.025 & - \\
$\beta$ & 0.025 & - \\
\hline$T_{\text {in_min }}$ & 16 (winter) & \\
& 22 (summer) & ${ }^{\circ} \mathrm{C}$ \\
$T_{\text {in_max }}$ & 22 (winter) & \\
\hline
\end{tabular}

The technical parameters, in terms of PGU, AC, and HP, are shown in Table 4. Additionally, to simulate the off-design performance of the PGU, naturally aspirated ICE data from the American Society of Heating, Refrigerating and Air-Conditioning Engineers were adopted in Wei et al. [32], thereby obtaining the electrical efficiency and thermal efficiency parameters. The SP system parameters are listed in Table 5. The specific time-of-use electricity price is used to calculate the grid interaction cost, which is given in Table 6. The price of natural gas is fixed at $0.367 \mathrm{CNY} / \mathrm{kWh}$. The GHG emissions coefficients for network electricity and natural gas used to calculate the ERR are shown in Table 7. Typical winter and summer days are selected as the simulation conditions, with each divided into 24 equal periods, and are shown in Figure 3. The output power of the PV panels and the typical daily outdoor temperature curve are shown in Figure 4. Smart appliances are considered schedulable load and their operational parameters are listed in Table 8. The relevant parameters of the GA are shown in Table 9. The problem was solved using the MATLAB GA toolbox on a computer configured with win7 64-bit i3-3240, MATLAB version is R2014a, and the software vendor is MathWorks of Natick, Massachusetts.

Table 4. Technical parameters of the systems.

\begin{tabular}{|c|c|c|c|c|c|}
\hline System & Device & Parameter & Value & Unit & Sources \\
\hline \multirow{10}{*}{ CCHP System } & \multirow{7}{*}{ PGU } & $\lambda$ & 0.22 & - & \multirow{7}{*}{ [32] } \\
\hline & & $a_{0}$ & 0.7361 & - & \\
\hline & & $a_{1}$ & 0.3016 & - & \\
\hline & & $a_{2}$ & -0.1193 & - & \\
\hline & & $b_{0}$ & 0.03998 & - & \\
\hline & & $b_{1}$ & 0.7597 & - & \\
\hline & & $b_{2}$ & -0.5147 & - & \\
\hline & $\mathrm{AC}$ & COP & 0.7 & - & [31] \\
\hline & \multirow{2}{*}{$\mathrm{HP}$} & $\mathrm{COP}_{h}$ & 3 & - & \multirow{2}{*}{ [33] } \\
\hline & & $C O P_{c}$ & 3 & - & \\
\hline \multirow{2}{*}{ SP System } & Gas boiler & $\eta_{b}$ & 0.8 & - & [15] \\
\hline & $\mathrm{EC}$ & $\mathrm{COP}_{e}$ & 3 & - & [33] \\
\hline
\end{tabular}


Table 5. Optional capacities of device.

\begin{tabular}{ccc}
\hline Device & Parameter & Capacities $(\mathbf{k W})$ \\
\hline PGU & $E_{\text {pgu,nom }}$ & 30 \\
AC & $C_{a c \_m a x}$ & 50 \\
\hline \multirow{2}{*}{ HP } & $Q_{h p \_m a x}$ & 70 \\
& $C_{h p \_m a x}$ & 50 \\
\hline Electric chiller & $C_{e c \_m a x}$ & 60 \\
Gas boiler & $Q_{b \_ \text {max }}$ & 80 \\
\hline
\end{tabular}

Table 6. Time-of-use price of electricity.

\begin{tabular}{ccc}
\hline Time & Electricity Price Period & $\begin{array}{c}\text { Electricity Price } \\
\text { (CNY/kWh) }\end{array}$ \\
\hline$[1,7),[22,24]$ & Valley price period & 0.363 \\
{$[7,11),[14,19)$} & Average price period & 0.687 \\
{$[11,14),[19,22)$} & Peak price period & 1.069 \\
\hline
\end{tabular}

Table 7. Parameters for the GHG emissions coefficients [15,34,35].

\begin{tabular}{|c|c|c|}
\hline \multirow{2}{*}{ GHG } & \multicolumn{2}{|c|}{ Emission Coefficients } \\
\hline & Network Electricity (g/kWh) & Natural Gas (g/kWh) \\
\hline $\mathrm{CO}_{2}$ & 968 & 220 \\
\hline $\mathrm{NO}_{X}$ & 0.5 & 0.019 \\
\hline $\mathrm{SO}_{2}$ & 2.1 & $2.62 \times 10^{-4}$ \\
\hline $\mathrm{CH}_{4}$ & 0.48 & 0.31 \\
\hline
\end{tabular}

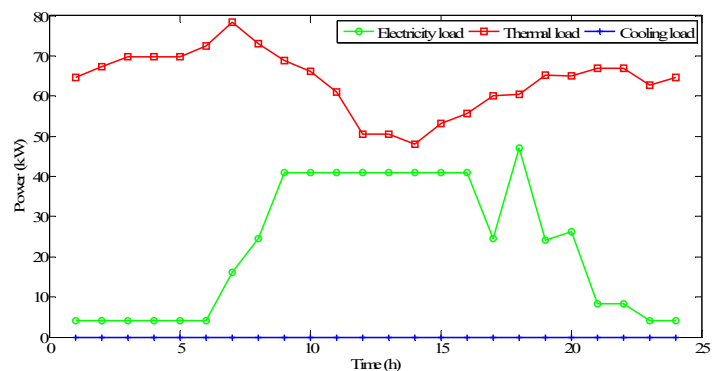

(a)

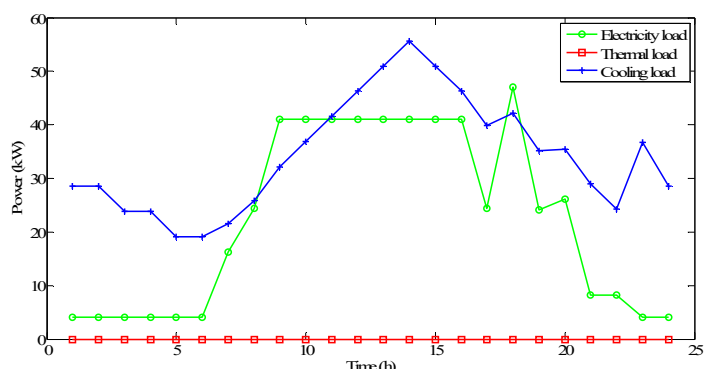

(b)

Figure 3. Typical daily heating, cooling, and electricity loads: (a) Typical daily loads in winter; (b) Typical daily loads in summer.

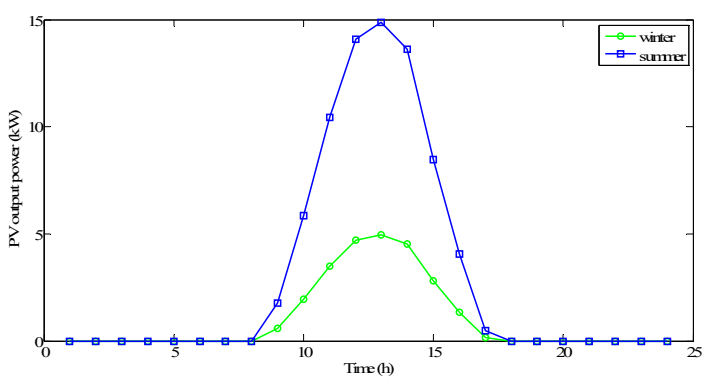

(a)

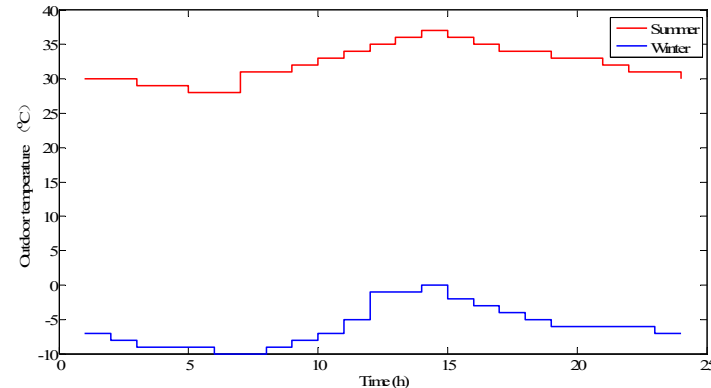

(b)

Figure 4. Output power of PV panels (a) and outdoor temperatures (b) on typical winter and summer days. 
Table 8. Operational parameters of appliances.

\begin{tabular}{ccccc}
\hline $\begin{array}{c}\text { Schedulable } \\
\text { Loads }\end{array}$ & $\begin{array}{c}\text { Fixed Time } \\
\text { Window }\end{array}$ & Scheduling Time Window & $\begin{array}{c}\text { Running } \\
\text { Time (h) }\end{array}$ & $\begin{array}{c}\text { Power } \\
\text { (kW) }\end{array}$ \\
\hline EV & {$[18,21]$} & {$[5,9],[11,15],[18,24]$} & 3 & 6 \\
Cleaning robot & {$[20,21]$} & {$[6,9],[17,21]$} & 1 & 2 \\
Dishwasher & {$[19,20]$} & {$[6,9],[18,24]$} & 1 & 2 \\
Washer & {$[20,21]$} & {$[5,9],[11,15],[18,22]$} & 1 & 2 \\
\hline
\end{tabular}

Table 9. Parameters of the genetic algorithm.

\begin{tabular}{cc}
\hline Parameter & Value \\
\hline Generations & 500 \\
Population Size & 500 \\
Mutation probability & 0.35 \\
Crossover probability & 0.8 \\
\hline
\end{tabular}

\subsection{Results and Analysis}

The typical daily optimization results for the four winter and summer case studies are shown in Table 10. The proposed collaborative optimization strategy (case 4) performs better in terms of the PESR, ERR, and OCSR than the other three operating modes. According to case 1, compared with SP system, CCHP system has greater advantages in energy, environmental and economic indexes. With the addition of TES and DR, the problem of system supply and demand mismatches has been reduced, and the performance of CCHP systems has been further improved. This paper mainly studies the effect of schedulable cooling and heating load and DR on reducing the mismatch between supply and demand of CCHP system and improving the performance of the system. Therefore, case 3 is taken as the main comparison object, while case 4 is the main research object for detailed analysis.

Table 10. Typical daily optimization results for four cases in winter and summer.

\begin{tabular}{ccccc}
\hline Season & Case Studies & PESR & ERR & OCSR \\
\hline \multirow{4}{*}{ Winter } & Case 1 & 0.4804 & 0.6117 & 0.4296 \\
& Case 2 & 0.4848 & 0.6180 & 0.4326 \\
& Case 3 & 0.4935 & 0.6260 & 0.4412 \\
& Case 4 & 0.5225 & 0.6446 & 0.4752 \\
\hline \multirow{3}{*}{ Summer } & Case 1 & 0.3801 & 0.5807 & 0.2677 \\
& Case 2 & 0.3861 & 0.5888 & 0.2723 \\
& Case 3 & 0.3875 & 0.5923 & 0.2854 \\
& Case 4 & 0.4619 & 0.6582 & 0.3327 \\
\hline
\end{tabular}

The optimal winter heating and electricity schedule for case 3 is shown in Figure 5. The system purchases a small amount of electricity from the grid at 9:00 and 18:00. At this time, PGU is working at a relatively high power state, and it still could not meet the electricity demand under the condition of fully utilizing the electricity generated by PGU and RESs. Most of the time, the system does not need to purchase electricity from the grid, the system cannot sell electricity to the grid, and the excess electricity can only be used and stored through the HP into the heating energy. The PGU generates extra electric energy from 02:00-04:00, 06:00-07:00, 15:00 and 17:00, converting it into heating energy for storage using the heat pump. The thermal storage tank releases energy from 05:00, 8:00-11:00, 16:00 and 18:00 to meet the heating load. At 05:00, the PGU is turned off because the electric load is low (below the PGU opening threshold) and the storage capacity of the thermal storage tank does not have much available storage capacity. The energy is released from the thermal storage tank to meet the heat load demand, the RESs meet most of the electrical load, and the remainder is purchased from the grid. The heating load from 8:00-19:00 is satisfied mainly by the PGU, with the remainder supplemented by 
the HP and thermal storage tank. With the decrease in the electric load between 20:00 and 24:00, the heating load is predominantly satisfied by energy generated by the HP. However, it incorporates an energy storage link that leads to an energy loss because the storage efficiency of the heat storage tank is less than $100 \%$ and further complicates the structure of the system.

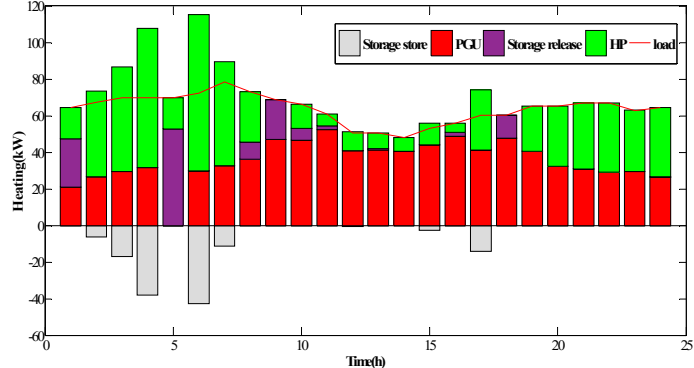

(a)

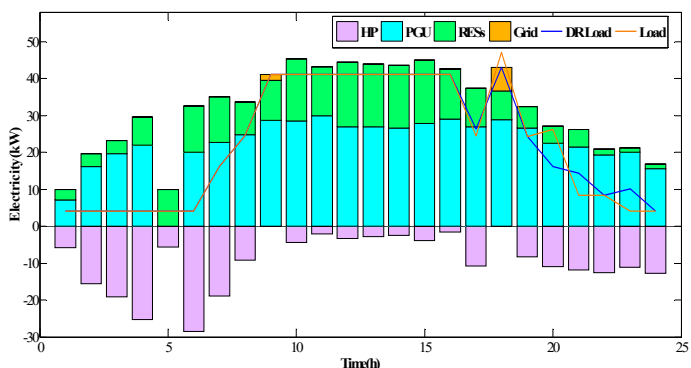

(b)

Figure 5. Optimal schedules for (a) heating and (b) electricity in case 3 in winter.

The optimal winter heating and electricity schedule optimization results for case 4 are shown in Figure 6. The collaborative scheduling strategy removes the energy storage link from case 3 and increases the scheduling of heating and cooling loads under the constraint of the comfort range. In contrast to case 3, the heating load of the optimized system increases at 03:00, 6:00 and 23:00, and the HP consumes more electricity to generate more heating energy, thus improving the PGU load ratio. As the heating load at any moment is related to the indoor temperature at the previous moment, the heating load required at 04:00 will be reduced if the indoor temperature is increased at 03:00. After optimization, the heating load of the system is reduced between 07:00 and 22:00 and the heating load is predominantly satisfied by the heat generated by the HP from 01:00 to 07:00. Therefore, the collaborative scheduling strategy (case 4) simplifies the system structure and achieves better performance indexes.

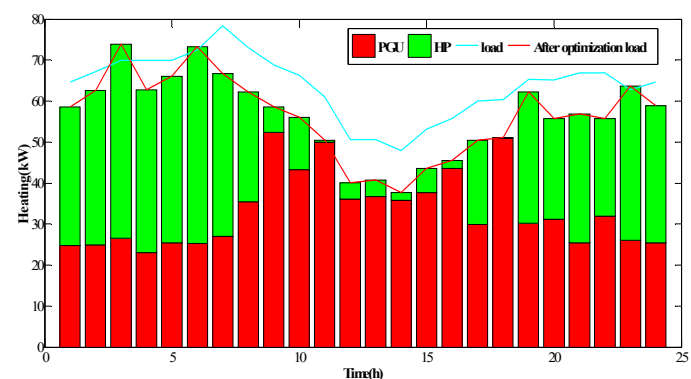

(a)

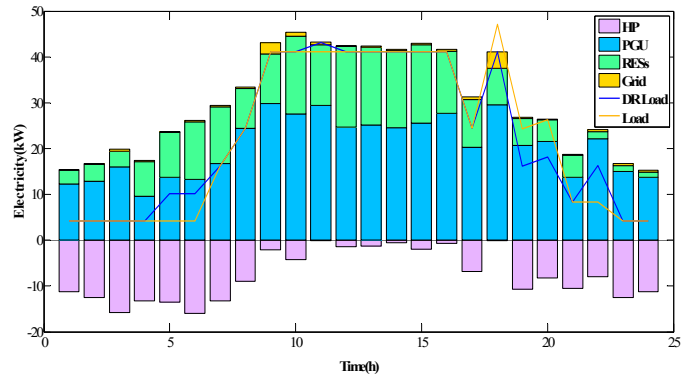

(b)

Figure 6. Optimal schedules for (a) heating and (b) electricity for case 4 in winter.

The optimal summer cooling and electricity schedule for cases 3 and 4 are shown in Figures 7 and 8 , respectively. For case 3, electricity generated by RESs account for a large proportion of the electrical load because the latter is low at 01:00-06:00 and 22:00-24:00; therefore, the opening threshold of the PGU is not reached and it is always in the "off" state. When the electricity generated by the PGU and RESs exceeds the load demand, the HP is converted into cooling load storage. When power supply is insufficient, the power purchased from the grid meets the remaining electrical load. For case 4, after optimization, the cooling load of the system is reduced between 01:00 and 06:00, which reduces the purchase of power from the grid. According to the cooling load model, the indoor temperature at 6:00 is related to the cooling load at next moment the, so the cooling load is higher at 7:00. As can be seen from the optimization results in Figures 6 and 8, the proposed optimal scheduling strategy (demonstrated in case 4) can implement resource scheduling from both the supply and demand sides and improve the PESR, ERR, and OCSR by $7.44 \%, 6.59 \%$, and $4.73 \%$ in summer, respectively. 


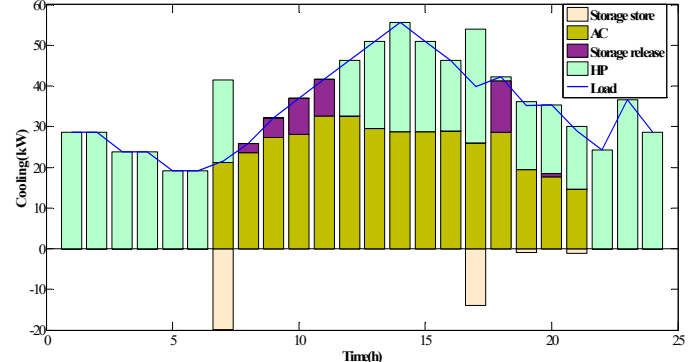

(a)

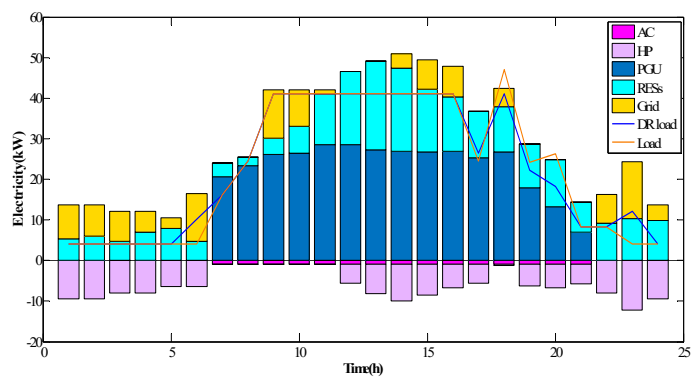

(b)

Figure 7. Optimal schedules for (a) cooling and (b) electricity for case 3 in summer.

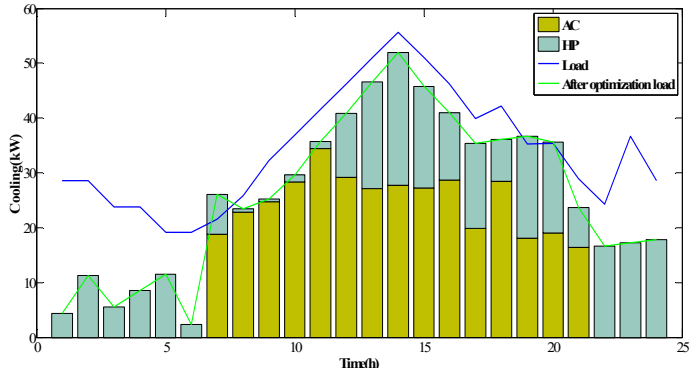

(a)

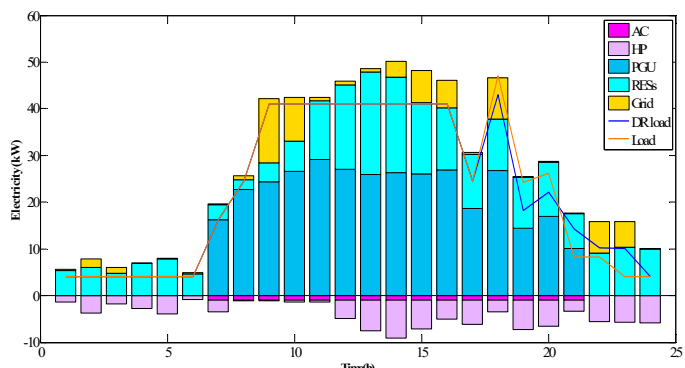

(b)

Figure 8. Optimal schedules for (a) cooling and (b) electricity for case 4 in summer.

\section{Conclusions}

This paper presents a multi-energy complementary CCHP system that combines RESs and schedulable loads. A gas-fired internal combustion engine generator set, PV panels, WTs, and the utility grid comprise the energy side of the system, while a collaborative optimal scheduling model that coordinates multiple energy sources, CCHP, and schedulable loads was proposed to simultaneously satisfy the demand for cooling, heating, and electricity. The system uses schedulable loads instead of energy storage, at the same time, smart residential appliances were introduced as the schedulable electrical loads to implement the DR program. Models for schedulable cooling and heating loads based on variable temperatures were then established. Furthermore, a multi-objective optimization method was established to determine the trade-off between the PESR, ERR, and OCSR performance indexes. Finally, a few cases were used to illustrate the feasibility and superiority of the proposed approach compared to the existing approaches. The major findings are summarized as follows:

(1) The collaborative optimal scheduling model can coordinate multiple energy sources, CCHP, and schedulable loads more efficiently than other models.

(2) Compared to the system using TES and DR, the PESR, ERR, and OCSR values of the proposed method are $7.44 \%, 6.59 \%$, and $4.73 \%$ higher, respectively, on a typical summer day.

(3) The proposed approach also simplifies the system structure and reduces the mismatch between the energy supply and demand.

Author Contributions: All the authors made contributions to the concept and design of the article. Conceptualization, X.G., F.L.; Methodology, X.G., B.S.; Software, X.G., D.L.; Resources, B.S.; Writing—Review \& Editing, B.S., F.L. All authors have read and agreed to the published version of the manuscript.

Funding: This work was supported by the National Natural Science Foundation of China (grant numbers 61821004, 61733010), Shandong Provincial Key Research and Development Program (Major Scientific and Technological Innovation Project) (NO.2019JZZY010901), and the Young Scholars Program of Shandong University (grant number 2016WLJH29).

Conflicts of Interest: The authors declare no conflict of interest. 


\section{References}

1. Han, J.; Ouyang, L.; Xu, Y.; Zeng, R.; Kang, S.; Zhang, G. Current status of distributed energy system in China. Renew. Sustain. Energy Rev. 2016, 55, 288-297. [CrossRef]

2. Liu, Q.; Lei, Q.; Xu, H.; Yuan, J. China's energy revolution strategy into 2030. Resour. Conserv. Recycl. 2018, 128, 78-89. [CrossRef]

3. Lu, S.; Li, Y.; Xia, H. Study on the configuration and operation optimization of CCHP coupling multiple energy system. Energy Convers. Manag. 2018, 177, 773-791. [CrossRef]

4. Wang, J.; Xie, X.; Lu, Y.; Liu, B.; Li, X. Thermodynamic performance analysis and comparison of a combined cooling heating and power system integrated with two types of thermal energy storage. Appl. Energy 2018, 219, 114-122. [CrossRef]

5. Lizana, J.; Chacartegui, R.; Barrios-Padura, A.; Ortizc, C. Advanced low-carbon energy measures based on thermal energy storage in buildings: A review. Renew. Sustain. Energy Rev. 2018, 82, 3705-3749. [CrossRef]

6. Xu, Z.; Guan, X.; Jia, Q.; Wu, J.; Wang, D.; Chen, S. Performance analysis and comparison on energy storage devices for smart building energy management. IEEE Trans. Smart Grid 2012, 3, 2136-2147. [CrossRef]

7. Liu, W.; Chen, G.; Yan, B.; Zhou, Z.; Du, H.; Zuo, J. Hourly operation strategy of a CCHP system with GSHP and thermal energy storage (TES) under variable loads: A case study. Energy Build. 2015, 93, 143-153. [CrossRef]

8. Mohammadkhani, N.; Sedighizadeh, M.; Esmaili, M. Energy and emission management of CCHPs with electric and thermal energy storage and electric vehicle. Therm. Sci. Eng. Progress 2018, 8, 494-508. [CrossRef]

9. Yang, C.; Meng, C.; Zhou, K. Residential electricity pricing in China: The context of price-based demand response. Renew. Sustain. Energy Rev. 2018, 81, 2870-2878. [CrossRef]

10. Aalami, H.A.; Moghaddam, M.P.; Yousefi, G.R. Demand response modeling considering Interruptible/Curtailable loads and capacity market programs. Appl. Energy 2010, 87, 243-250. [CrossRef]

11. Fotouhi Ghazvini, M.A.; Soares, J.; Abrishambaf, O.; Castro, R.; Vale, Z. Demand response implementation in smart households. Energy Build. 2017, 143, 129-148. [CrossRef]

12. Zakariazadeh, A.; Jadid, S.; Siano, P. Smart microgrid energy and reserve scheduling with demand response using stochastic optimization. Electr. Power Energy Syst. 2014, 63, 523-533. [CrossRef]

13. Gao, L.; Hwang, Y.; Cao, T. An overview of optimization technologies applied in combined cooling, heating and power systems. Renew. Sustain. Energy Rev. 2019, 114, 109344. [CrossRef]

14. Jradi, M.; Riffat, S. Tri-generation systems: Energy policies, prime movers, cooling technologies, configurations and operation strategies. Renew. Sustain. Energy Rev. 2014, 32, 396-415. [CrossRef]

15. Wang, J.; Jing, Y.; Zhang, C.; Zhai, Z. Performance comparison of combined cooling heating and power system in different operation modes. Appl. Energy 2011, 88, 4621-4631. [CrossRef]

16. Song, X.; Liu, L.; Zhu, T.; Zhang, T.; Wu, Z. Comparative analysis on operation strategies of CCHP system with cool thermal storage for a data center. Appl. Therm. Eng. 2016, 108, 680-688. [CrossRef]

17. Wang, J.; Sui, J.; Jin, H. An improved operation strategy of combined cooling heating and power system following electrical load. Energy 2015, 85, 654-666. [CrossRef]

18. Feng, L.; Dai, X.; Mo, J.; Ma, Y.; Shi, L. Analysis of energy matching performance between CCHP systems and users based on different operation strategies. Energy Convers. Manag. 2019, 182, 60-71. [CrossRef]

19. Ma, W.; Fang, S.; Liu, G. Hybrid optimization method and seasonal operation strategy for distributed energy system integrating CCHP, photovoltaic and ground source heat pump. Energy 2017, 141, 1439-1455. [CrossRef]

20. Cao, T.; Hwang, Y.; Radermacher, R. Development of an optimization based design framework for microgrid energy systems. Energy 2017, 140, 340-351. [CrossRef]

21. Luo, Z.; Wu, Z.; Li, Z.; Cai, H.; Li, B.; Gu, W. A two-stage optimization and control for CCHP microgrid energy management. Appl. Therm. Eng. 2017, 125, 513-522. [CrossRef]

22. Faridoddin Afzali, S.; Mahalec, V. Optimal design, operation and analytical criteria for determining optimal operating modes of a CCHP with fired HRSG, boiler, electric chiller and absorption chiller. Energy 2017, 139, 1052-1065. [CrossRef]

23. Li, F.; Sun, B.; Zhang, C.; Liu, C. A hybrid optimization-based scheduling strategy for combined cooling, heating, and power system with thermal energy storage. Energy 2019, 188, 115948. [CrossRef] 
24. Deng, N.; Cai, R.; Gao, Y.; Zhou, Z.; He, G.; Liu, D.; Zhang, A. A MINLP model of optimal scheduling for a district heating and cooling system: A case study of an energy station in Tianjin. Energy 2017, 141, 1750-1763. [CrossRef]

25. Zheng, C.Y.; Wu, J.Y.; Zhai, X.Q.; Wang, R.Z. A novel thermal storage strategy for CCHP system based on energy demands and state of storage tank. Int. J. Electr. Power Energy Syst. 2017, 85, 117-129. [CrossRef]

26. Kuang, J.; Zhang, C.; Li, F.; Sun, B. Dynamic Optimization of Combined Cooling, Heating, and Power Systems with Energy Storage Units. Energies 2018, 11, 2288. [CrossRef]

27. Li, F.; Sun, B.; Zhang, C.; Zhang, L. Operation optimization for combined cooling, heating, and power system with condensation heat recovery. Appl. Energy 2018, 230, 305-316. [CrossRef]

28. Vlot, M.C.; Knigge, J.D.; HanSlootweg, J.G. Economical regulation power through load shifting with smart energy appliances. IEEE Trans. Smart Grid 2013, 4, 1705-1712. [CrossRef]

29. Wu, C.; Gu, W.; Xu, Y.; Jiang, P.; Lu, S.; Zhao, B. Bi-level optimization model for integrated energy system considering the thermal comfort of heat customers. Appl. Energy 2018, 232, 607-616. [CrossRef]

30. Zeng, M.; Qian, Q.; Wang, H.; Gao, L.; Guo, Y.; Zhang, L. Economy benefit comparison of CCHP system and conventional separate supply system. In Proceedings of the 2015 8th International Conference on Intelligent Computation Technology and Automation (ICICTA), Nanchang, China, 14-15 June 2015; IEEE: New York, NY, USA, 2015; pp. 402-406.

31. Zeng, R.; Li, H.; Jiang, R.; Liu, L.; Zhang, G. A novel multi-objective optimization method for CCHP-GSHP coupling systems. Energy Build. 2016, 112, 149-158. [CrossRef]

32. Wei, D.; Chen, A.; Sun, B.; Zhang, C. Multi-objective optimal operation and energy coupling analysis of combined cooling and heating system. Energy 2016, 98, 296-307. [CrossRef]

33. Zhou, Z.; Liu, P.; Li, Z.; Ni, W. An engineering approach to the optimal design of distributed energy systems in China. Appl. Therm. Eng. 2013, 53, 387-396. [CrossRef]

34. Man, Y.; Han, Y.; Hu, Y.; Yang, S.; Yang, S. Synthetic natural gas as an alternative to coal for power generation in China: Life cycle analysis of haze pollution, greenhouse gas emission, and resource consumption. J. Clean. Prod. 2018, 172, 2503-2512. [CrossRef]

35. Huang, B.; Zhao, J.; Geng, Y.; Tian, Y.; Jiang, P. Energy-related GHG emissions of the textile industry in China. Resour. Conserv. Recycl. 2017, 119, 69-77. [CrossRef]

(C) 2020 by the authors. Licensee MDPI, Basel, Switzerland. This article is an open access article distributed under the terms and conditions of the Creative Commons Attribution (CC BY) license (http://creativecommons.org/licenses/by/4.0/). 